\title{
Agreement between rectal and vaginal temperature measured with temperature loggers in dairy cows
}

\author{
Vishal Suthar, Onno Burfeind, Britta Maeder and Wolfgang Heuwieser* \\ Clinic for Animal Reproduction, Faculty of Veterinary Medicine, Freie Universität Berlin, Koenigsweg 65, 14163 Berlin, Germany
}

Received 1 June 2012; accepted for publication 9 January 2013

\begin{abstract}
The overall objective of this study was to evaluate agreement between rectal (RT) and vaginal temperature (VT) measured with the same temperature loggers in dairy cows. Three experiments were conducted. The study began with a validation in vitro of 24 temperature loggers comparing them to a calibrated liquid-in-glass thermometer as a reference method. The association and agreement between the 24 temperature loggers with the reference method was $r=0.996(P<0 \cdot 001)$ with a negligible coefficient of variance $(0 \cdot 005)$ between the loggers. In-vivo temperature loggers were tested in 11 healthy post-partum cows (Experiment 2) and 12 early post-partum cows with greater body temperature (Experiment 3). Temperature loggers were set to record VT and RT at 1-min intervals. To prevent rectal and vaginal straining and potential expulsion of temperature logger an epidural injection of $2.5 \mathrm{ml}$ of $2 \%$ Procain was administered. Association between RT and VT was $r=0.92(P<0.001$; Experiment 2$)$ and $r=0.94(P<0.001$; Experiment 3$)$ with a negligible difference of -0.1 and $0.01^{\circ} \mathrm{C}$. Bland-Altman plots demonstrated agreement between RT and VT for healthy and early post-partum cows with greater body temperature in Experiments 2 and 3, respectively. Furthermore the intra-class correlation coefficient between RT and VT measured with identical loggers within cows of Experiments 2 and 3 also demonstrated greater agreements $(P<0 \cdot 001)$. Therefore, continuous VT monitoring with temperature loggers can be used as a measure of body temperature in dairy cows.
\end{abstract}

Keywords: Dairy cow, rectal, vaginal, temperature.

Extensive work has been published on rectal temperature (RT) to identify early post-partum illness (Drillich et al. 2001; Wenz et al. 2011), oestrus (Wrenn et al. 1958; Rajamahendran et al. 1989), parturition (Wrenn et al. 1958, 1961) and heat stress (Suthar et al. 2012a) in dairy cows. Recently, confounders such as inter or intra-observer variability, thermometer and penetration depth have been demonstrated to affect the repeatability of RT measurements (Burfeind et al. 2010). To obtain body temperature (BT) measurements in higher frequency without human interference, automatic monitoring methods for BT were used. These included surgical implantation of digital thermistors (Bitman et al. 1984) or transmitters with radio-telemetry units (Lammoglia et al. 1997; Lefcourt \& Adams, 1998; AlZahal et al. 2011) in various anatomical locations (i.e. subcutaneously at the left flank, peritoneal cavity, udder, rumen). These approaches provided valuable insights into regulation of BT but were invasive and the equipment cumbersome.

*For correspondence; e-mail: w.heuwieser@fu-berlin.de
Therefore, non-surgical methods utilized BT monitoring units fitted into the rectum with a harness (Reuter et al. 2010), placed in the rumen (Rose-Dye et al. 2011), the reticulum (Bewley et al. 2008) or tympanic cavity in the middle ear (Bergen \& Kennedy, 2000).

Our group (Vickers et al. 2010; Burfeind et al. 2011; Suthar et al. 2011) and others (Kendall et al. 2006; Dikmen et al. 2008; Kendall \& Webster, 2009) have successfully used vaginal data loggers for continuous monitoring of BT. Recently, this approach has been validated in vitro and in vivo (Vickers et al. 2010). RT was measured in vivo with a digital thermometer at 3-h intervals and compared with an average vaginal temperature (VT) calculated from 18 observations measured over the corresponding 3-h interval. Coefficients of correlation for peak lactating and sick postpartum cows were 0.46 and 0.75 , respectively. The coefficient of correlation between RT and VT was found to be increased $(r=0 \cdot 85, P<0 \cdot 001)$ when the two measurements were separated by less than $10 \mathrm{~min}$. Interestingly the coefficient of correlation between RT and VT was found to be less related $(r=0.72, P<0.001)$ when the two measures were separated by $20 \mathrm{~min}$. In this study VT of early post-partum 
healthy ( $n=7$ cows) and with retained placenta ( $n=7$ cows) and peak lactating ( $n=13$ cows) was $0 \cdot 0-0 \cdot 1 \pm 0 \cdot 1{ }^{\circ} \mathrm{C}$ greater than RT. For dry cows and lactating, non-pregnant cows the relationship between RT and VT was $0 \cdot 76-0 \cdot 89$ and $0 \cdot 71-$ 0.86, respectively (Burfeind et al. 2011; Suthar et al. 2012b). In both studies VT was $0 \cdot 2 \pm 0.05{ }^{\circ} \mathrm{C}$ to $0 \cdot 2 \pm 0 \cdot 2{ }^{\circ} \mathrm{C}$ greater than RT.

All these studies measured VT in 5-10-min intervals and calculated means for 1-4-h intervals to demonstrate associations with RT measured hourly to every $4 \mathrm{~h}$. This approach, albeit plausible, might affect the reported associations. Furthermore, most authors have used a digital thermometer to measure RT for validation of vaginal, reticular, ruminal or udder temperature monitored with data loggers or radio transmitters. Thus the reported correlations between two anatomical locations were biased by two different technologies. Therefore the objective of this study was to evaluate agreement between RT and VT measured with identical temperature data loggers.

\section{Materials and methods}

Three experiments were conducted between September and November 2011. All procedures for this study were in accordance with the Institutional Animal Care and Use Committee.

\section{Experiment 1}

The study began with an in-vitro phase evaluating variation among loggers. Twenty four different microprocessor controlled temperature loggers (Minilog 8, Vemco Ltd., Halifax, Canada; Size $=92 \mathrm{~mm} \times 20 \mathrm{~mm}$; weight $=40.5 \mathrm{~g})$ and a calibrated liquid-in-glass thermometer (validated by the Office of Legal Metrology of the State of Hessen, Germany; Type E 0.1/0/50 DIN 12775; Serial number 3636; Verification Certificate 5-3636-09) were placed into the same water bath (Julabo, Thermostate Electron Corporation, Karlsruhe, Germany). The temperature loggers measured temperature from 0 to $+45^{\circ} \mathrm{C}$ with an accuracy of $\pm 0.3^{\circ} \mathrm{C}$ and a resolution of $0.2^{\circ} \mathrm{C}$. The water bath contained $3.5 \mathrm{I}$ of water adjusted to $37^{\circ} \mathrm{C}$. Temperature loggers were programmed to record measurements in 1-min intervals. Twelve observations were made at each degree increment from 37 to $44{ }^{\circ} \mathrm{C}$ with a defined $7 \pm 1$-min incubation period to validate 24 loggers. The water bath temperature was measured with the calibrated liquid-in-glass thermometer and used as a reference method. Before initiating this experiment the lag period between the temperature sensor of water bath and temperature of the liquid in-glass thermometer was determined. The average lag period was between the stabilization of sensor temperature of water bath and the reference method temperature was $1 \pm 1$-min. To assure correct measurements of temperature we decided to use $7 \pm 1$-min incubation period after each temperature increase (i.e. $37 \cdot 0-$ $44.0{ }^{\circ} \mathrm{C}$ in $1.0{ }^{\circ} \mathrm{C}$ increments.
For studying agreement between RT and VT two experiments were conducted in vivo using the temperature loggers validated in Experiment 1.

\section{Experiment 2}

This experiment was performed with 11 lactating $[135 \pm 56$, days in milk (DIM); mean \pm SD] healthy, postpartum, multiparous, non-pregnant cows at the Clinic for Animal Reproduction, Freie Universität Berlin, Germany. Before enrolment the health status of the cows was evaluated on the bases of 2 months of disease and treatment records and cows were clinically examined on the day of enrolment. Only cows which had not been diagnosed or treated for infectious or metabolic or both diseases were enrolled. In mid-lactation BT of cows remained in the normal range (i.e. 37-39 ${ }^{\circ} \mathrm{C}$; Kendall \& Webster, 2009). All cows were housed in a tie stall barn with deep bedding (i.e. chopped straw and lime) and fed twice daily with grass-silage, grass hay, and concentrate and mineral mix.

\section{Experiment 3}

Vickers et al. (2010) demonstrated that early post-partum cows have greater body temperature than peak lactation cows. Considering these differences, and since the nature of Experiment 2 did not allow us to draw inference on cows with elevated BT, another experiment was performed including twelve early post-partum $(3 \pm 1$, DIM) multiparous cows at a commercial dairy farm in Sachsen-Anhalt in Germany.

All cows were housed in a free stall facility with slotted floors and equipped with rubber mats. The cows were fed a total mixed ration consisting of $41.9 \%$ concentrate and mineral $\operatorname{mix}, 31 \cdot 2 \%$ corn silage, $24.4 \%$ grass silage and $2.5 \%$ barley straw on a dry matter basis (net energy for lactation, $\mathrm{NEL}=7.03 \mathrm{MJ} / \mathrm{kg}$ dry matter) distributed with a conveyer belt system 10 times a day. Cows were milked 3 times daily.

During both experiments performed in vivo, ambient temperature $(\mathrm{AT})$ and relative humidity $(\mathrm{RH})$ of the experimental pen were recorded every minute using a Tinytag Plus II logger (Gemini loggers Ltd, Chichester, West Sussex, UK) which was secured at a beam $3 \mathrm{~m}$ above the ground. The temperature humidity index (THI) was calculated according to the equation reported by Kendall et al. (2008): $\mathrm{THI}=$ $(1 \cdot 8 \times \mathrm{AT}+32)-\{(0 \cdot 55-0 \cdot 0055 \times \mathrm{RH}) \times(1 \cdot 8 \times \mathrm{AT}-26)\}$.

In Experiments 2 and 3, temperature loggers were set to record temperature at 1 -min intervals. For VT monitoring temperature loggers were attached to a progesterone-free modified vaginal controlled internal drug release (Pfizer Animal Health, Berlin, Germany; CIDR) and inserted into the vaginal cavity. For RT monitoring temperature loggers were inserted into the rectum without a CIDR after removing the manure with a lubricated gloved hand. After insertion of the loggers into the vagina and rectum, the first $10 \mathrm{~min}$ of observations of temperatures were removed to assure that 
confounding due to lag effect of the logger due to influx of ambient air was eliminated. If vaginal and rectal loggers were retained inside at least $20 \pm 10 \mathrm{~min}$ an epidural injection of $2.5 \mathrm{ml}$ of Procain (2\% Procasel, Selectavet, Dr Otto Fischer; GmbH, Weyarn-Holzolling, Germany) was administered to prevent rectal and vaginal pressing. If both temperature loggers were retained at least for $80 \pm 10 \mathrm{~min}$ after epidural injection data were used for analyses. There is evidence (Skarda \& Muir, 1979; Day \& Skarda, 1991) that epidural anaesthesia changes the blood flow. However in our preliminary analyses we did not observe any effect on BT.

\section{Statistical analysis}

To minimize statistical bias for Experiments 2 and 3 the required sample size was calculated using $\mathrm{G}^{*}$ Power software (http://www.psycho.uni-duesseldorf.de/abteilungen/aap/ gpower3/download-and-register). Considering previous studies (Vickers et al. 2010; Burfeind et al. 2011; Suthar et al. 2011) we hypothesized that the minimum achievable association between RT and VT in dairy cows would be 0.8 at $\alpha=0.05$ and $\beta=0.05$ level. Thus the minimum sample size for these experiments was 9 cows. Therefore 11 and 12 cows were enrolled, respectively in Experiments 2 and 3.

Data from temperature and THI loggers were downloaded into excel spreadsheets (Office 2010, Microsoft Deutschland $\mathrm{GmbH}$, Munich, Germany) and analysed using SPSS for Windows (Version 19.0, IBM Inc., IBM-Allee, Ehningen, Germany) and Medcalc (Version 12.0.3.0. MedCalc software, bvba, Mariakerke, Belgium). Rectal and vaginal temperature values $10 \mathrm{~min}$ after insertion and $10 \mathrm{~min}$ before removal of temperature loggers, respectively, were considered artefacts due to confounding by ambient temperature after logger movements and were excluded from the analyses.

The relationship between paired temperature observations of 24 loggers and the liquid-in-glass thermometer (reference method) was evaluated using Pearson's coefficient of correlation and linear regression whereas the mean difference was evaluated using a paired $t$ test. The logger level variation and relationship was explained using intra-class correlation coefficient. The relationships between AT, RH and THI with RT and VT, respectively were evaluated using Pearson's coefficient of correlation for the two experiments performed in vivo. The influence of AT, RH and THI on RT and VT of cows in Experiments 2 and 3 were tested in univariate analyses considering them as covariates. Relationship between VT and RT in the two experiments performed in vivo was evaluated using Pearson's coefficient of correlation and linear regression, respectively. Due to the fact that comparison of clinical measurements using coefficients of correlation can be inappropriate, the agreement between the temperature observations of 24 temperature loggers and the liquid-in-glass thermometer in Experiment 1 (in vitro) and between VT and RT observations in Experiment 2 and 3 (in vivo) were graphically analysed using the method described by Bland \& Altman (1986). It is also true that simple Pearson's correlations do not adequately describe the relationship between RT and VT measured with identical loggers within cows. One could get high correlations if cows varied in BT even if there was not a strong correlation between RT and VT within a cow. Therefore to compare agreement between RT and VT measures of individual cows of the two experiments performed in vivo the intra-class correlation coefficients using two-way mixed effects model, where RT and VT logger effects are taken as random and RT and VT observations effects are taken as fixed, were used. As per Field (2005) we interpreted intraclass correlation coefficient such as, $0-0 \cdot 2$ poor agreement; 0.3-0.4 fair agreement; 0.5-0.6 moderate agreement; $0 \cdot 7-0 \cdot 8$ strong agreement and $>0 \cdot 8$ almost perfect agreement.

Potential difference between RT and VT observations of cows in Experiment 2 and 3 (in vivo) was evaluated repeating observations (paired observations of RT and VT of cow) over period of time and random effect of cow was included in both models. Scaled identity covariance structure was used, because it resulted in the models with the lowest Akaike information criterion value. The LSD post-hoc procedure was performed to estimate the difference between RT and VT observations of cows in Experiment 2 and 3. The reported statistics were performed according to guidelines supplied by Watson \& Petrie (2010).

\section{Results and discussion}

Considering logger as the experimental unit, 96 paired observations per logger were generated and used to validate the temperature loggers in vitro (Experiment 1). The mean difference between the values recorded by the temperature loggers and the liquid-in-glass thermometer was significant but practically negligible $\left(0.06 \pm 0.1{ }^{\circ} \mathrm{C}, P<0.001\right)$. Also, there was a strong relationship between the temperature of the water bath measured with the liquid-in-glass thermometer and the recorded temperature of the loggers $(r=0.996$, $\left.P<0.001 ; R^{2}=992, P<0 \cdot 001\right)$. Inter-logger variation was small $(C V=0.005)$. The agreement between the paired observations of the gold standard and the 24 temperature loggers is shown in Fig. 1. The difference between temperature observations of the liquid-in-glass thermometer and the 24 loggers was negligible $0 \cdot 04 \pm 0 \cdot 1{ }^{\circ} \mathrm{C}(95 \% \mathrm{Cl}:-0 \cdot 16$ to $0.24^{\circ} \mathrm{C}$; Fig. 1). Furthermore we used intra-class correlation coefficient to evaluate an aggrement between temperatures of individual 24 loggers with liquid-in-glass thermometer (logger level). It demonstrated perfect agreements (intra-class correlation coefficient $=1 ; P<0 \cdot 001$ ).

After excluding $10 \mathrm{~min}$ of paired observations, after logger insertion and before logger removal, an average 169 14 and $167 \pm 16$ paired observations of RT and VT of individual cows could be used for analyses of Experiment 2 and 3, respectively. Ambient temperature and $\mathrm{RH}$ was $17 \cdot 2 \pm 0 \cdot 1^{\circ} \mathrm{C}$ and $67 \cdot 0 \pm 0 \cdot 8 \%$, and $12 \cdot 6 \pm 0 \cdot 1{ }^{\circ} \mathrm{C}$ and $83 \cdot 0 \pm 0 \cdot 2 \%$ in 


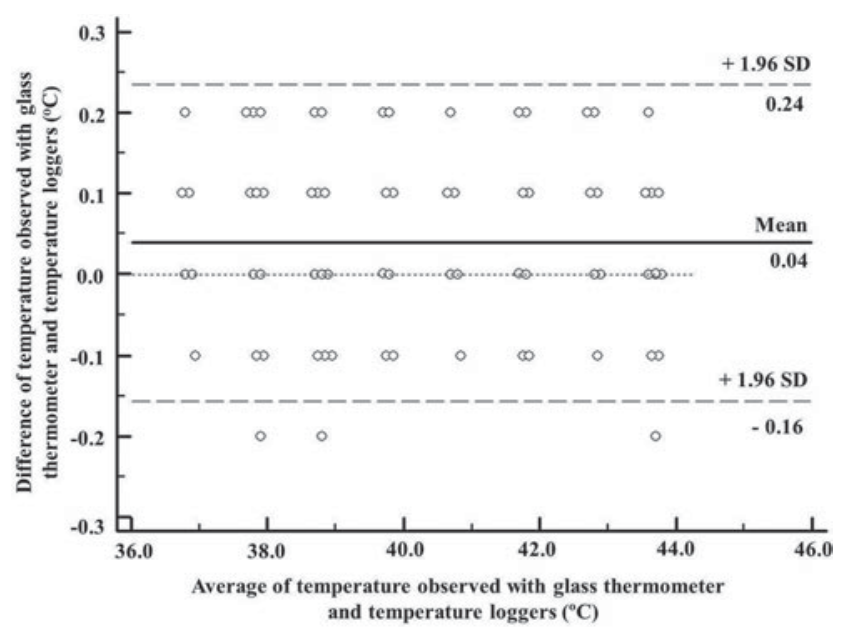

Fig. 1. Bland and Altman plot showing agreement between measurements of the liquid-in- glass thermometer as a reference method and the 24 temperature loggers in Experiment 1.

Experiments 2 and 3, respectively. The calculated THI in Experiments 2 and 3 were $62 \cdot 0 \pm 1 \cdot 0$ and $57 \cdot 5 \pm 0 \cdot 2$, respectively. Relationships between $\mathrm{BT}$ and $\mathrm{THI}$ in the two experiments in vivo did not exist (RT: $r=-0.005$, $P=0.824 ; r=-0.071, P<0.001$ and VT: $r=0.002, P=0.948$; $r=-0 \cdot 10, P=0 \cdot 01)$. Furthermore, in both the experiments an influence of $\mathrm{AT}, \mathrm{RH}$ and $\mathrm{THI}$ on RT and $\mathrm{VT}$ of experimental cows was not detected $(P<0 \cdot 5)$ and was removed from further analyses. The absence of relevant relationships between BT and $\mathrm{THI}$ is typical for relatively cool environmental conditions compared with other studies conducted in tropical climate (Kendall et al. 2006).

The mean $\left( \pm\right.$ SD) $38 \cdot 77 \pm 0 \cdot 23^{\circ} \mathrm{C}$ RT and $38.78 \pm 0 \cdot 24{ }^{\circ} \mathrm{C}$ VT was recorded in dairy cows of Experiment 2 whereas 39. $54 \pm 0.53{ }^{\circ} \mathrm{C}$ RT and $39.48 \pm 0.49^{\circ} \mathrm{C} V T$ was recorded dairy cows of Experiment 3. Overall, VT demonstrated $0 \cdot 01 \pm 0 \cdot 1^{\circ} \mathrm{C}$ greater temperature compared with RT in Experiment $2(P<0 \cdot 001)$, whereas VT demonstrated $0 \cdot 01 \pm 0 \cdot 1{ }^{\circ} \mathrm{C}$ lower temperature compared with RT of cows in Experiment $3(P<0 \cdot 001)$. Associations between RT and VT existed during Experiment 2 ( $n=1861$ paired observations, $r=0.92$, $P<0.001 ; R^{2}=0 \cdot 84, P<0 \cdot 001$; Figs. $2 \& 3$ ) and Experiment 3 $\left(n=2003\right.$ paired observations; $r=0.94, P<0.001 ; R^{2}=0.89$, $P<0.001$; Figs. $4 \& 5$ ). The intra-class correlation coefficient between RT and VT observation measured with identical loggers within cows ranges from 0.4 to $0.94(P<0.001)$ in Experiment 2. Specifically, 2 cows demonstrated moderate $(0 \cdot 4-0 \cdot 6)$ and 9 other cows demonstrated strong to perfect agreements (intra-class correlation coefficient $>0 \cdot 7$; $P<0 \cdot 01)$. Interestingly in cows with greater BT $\left(38-41 \cdot 4^{\circ} \mathrm{C}\right)$ of Experiment 3, intra-class correlation coefficient between $\mathrm{RT}$ and $\mathrm{VT}$ loggers within cows ranges from moderate $(0 \cdot 6)$ to perfect $(1 \cdot 0 ; P<0 \cdot 001)$. More specifically, 10 cows demonstrated strong $(0 \cdot 7-0 \cdot 8)$ to excellent $(\geqslant 0 \cdot 9)$ agreements, only 2 cows demonstrated moderate $(0 \cdot 6)$ agreements between RT and VT observations measured with identical loggers

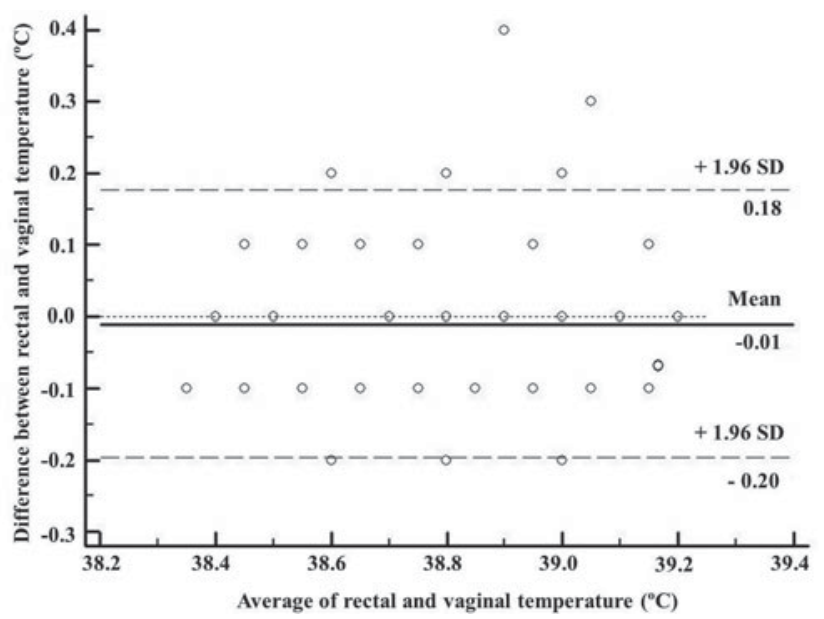

Fig. 2. Bland and Altman plot showing agreement between rectal and vaginal temperature measures of 11 healthy post-partum cows in Experiment 2.

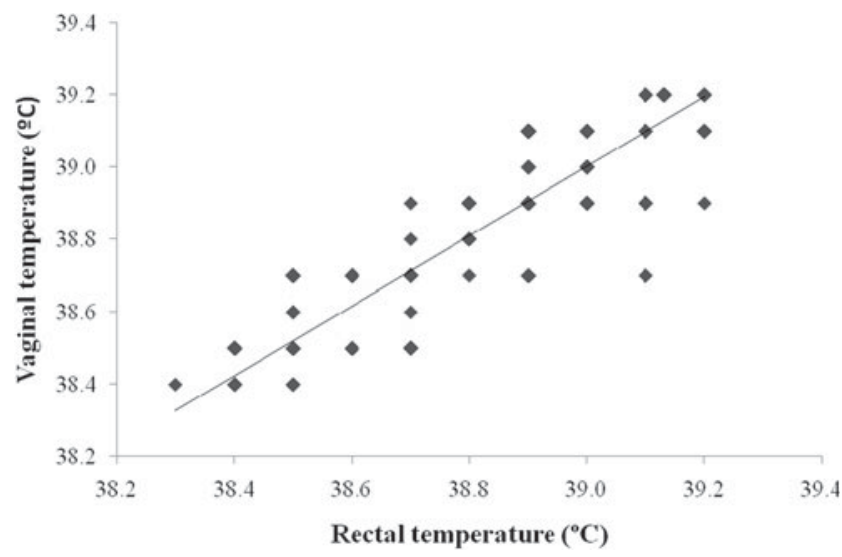

Fig. 3. Relationship between $n=1861$ paired observations of rectal and vaginal temperatures measured with identical loggers in 11 healthy cows of Experiment 2.

within cows. These results suggest that an agreement between RT and VT measured with identical loggers within cows during Experiment 2 and 3 is very high.

The associations between RT and VT measured using identical loggers during both experiments performed in vivo in this study were greater than those reported for early postpartum cows $(r=0 \cdot 81$; Vickers et al. 2010), peak lactation cows $(r=0.46$; Vickers et al. 2010), ante-partum cows $(r=0 \cdot 76-0 \cdot 89$; Burfeind et al. 2011), and pregnant cows $(r=0 \cdot 84 ; 180 \pm 5 d$; Suthar et al. 2012b). As we expected, the correlation and regression analysis of this study revealed that the BT values measured in the rectal and vaginal cavities using the identical temperature loggers is strongly associated in different stages of lactation (Experiment 2: $135 \pm 56$ DIM; Experiment 3: $3 \pm 1$ DIM). To visualize the distribution of differences between RT and VT Bland-Altman plots were used (Figs. 2 \& 4). In Experiment 2, the difference between 


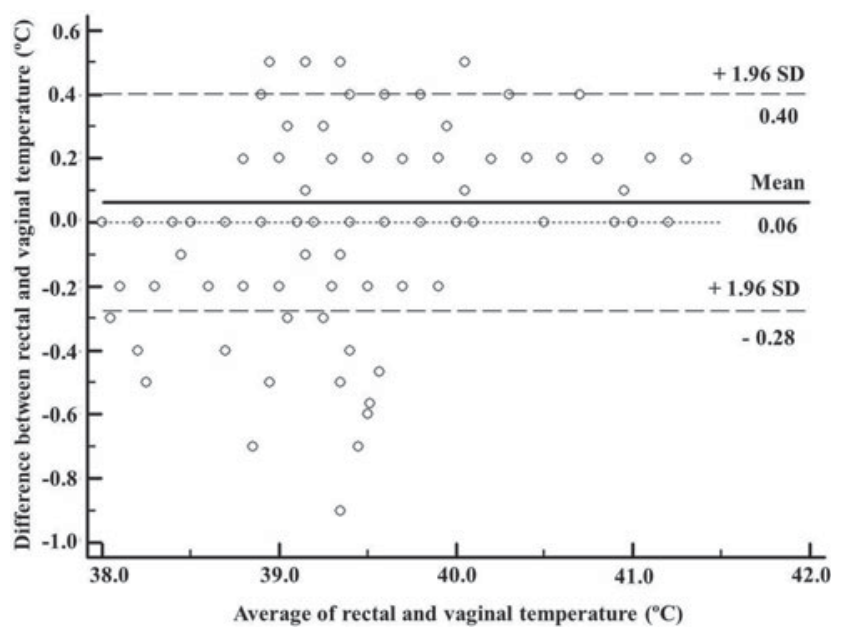

Fig. 4. Bland and Altman plot showing agreement between rectal and vaginal temperature measures of 12 early post-partum cows in Experiment 3.

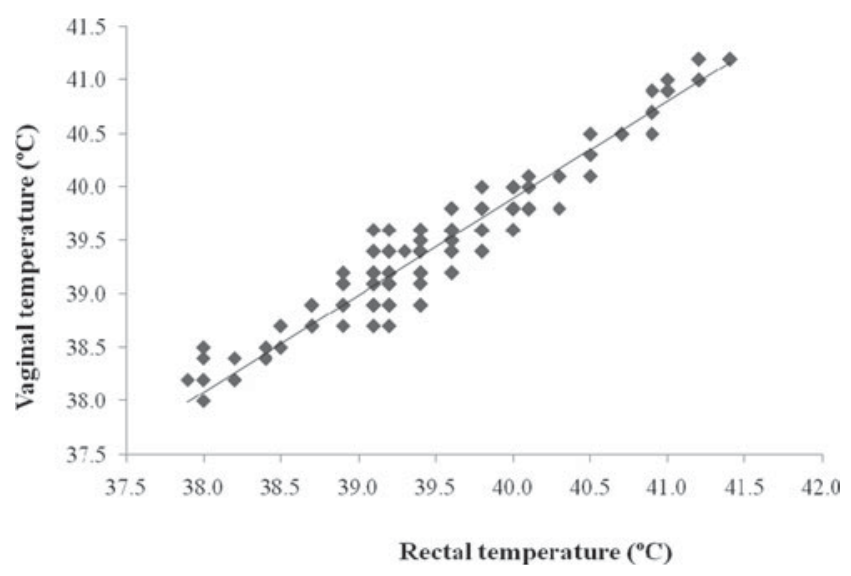

Fig. 5. Relationship between $n=2003$ paired observations of rectal and vaginal temperature measured with identical loggers in 12 early post-partum cows of Experiment 3.

RT and VT observations was $0 \cdot 01 \pm 0 \cdot 1^{\circ} \mathrm{C}$ with $-0 \cdot 2$ to $0.18{ }^{\circ} \mathrm{C}$ of $95 \% \mathrm{Cl}$ of lower and upper limit of difference (Fig. 2). Only 71 observations (3.8\%) were outside the $95 \%$ $\mathrm{Cl}$. Because in Experiment 2 only healthy post-partum cows with normal BT $\left(38 \cdot 4-39 \cdot 2{ }^{\circ} \mathrm{C}\right)$ were enrolled no inference could be made regarding the agreement between RT and VT for cows with greater temperature. Therefore in Experiment 3, 12 cows with greater temperature (mean RT $39 \cdot 5^{\circ} \mathrm{C}$ and VT $39.5{ }^{\circ} \mathrm{C}$; BT range 38.0 to $41.4{ }^{\circ} \mathrm{C}$ ) were enrolled. The difference between RT and VT observations was $0 \cdot 06 \pm 0.2{ }^{\circ} \mathrm{C}\left(95 \% \mathrm{Cl}:-0.28\right.$ to $0.4{ }^{\circ} \mathrm{C}$; Fig. 4). Only 93 $(4 \cdot 7 \%)$ observations were outside the $95 \% \mathrm{CI}$. We suspect that the wider range of the $95 \% \mathrm{Cl}$ in Experiment 3 was due to an enlarged vaginal cavity in early post-partum cows (3 \pm 1 DIM; Sheldon et al. 2008; Kahn \& Line, 2010). The observation that in early post-partum cows VT was negligibly $\left(0 \cdot 1 \pm 0 \cdot 1^{\circ} \mathrm{C}\right)$ lower than RT (Experiment 3), whereas VT was negligibly $\left(0 \cdot 01 \pm 0 \cdot 1^{\circ} \mathrm{C}\right)$ greater than $\mathrm{RT}$ in cows later in lactation (Experiment 2) might also be related to a more frequent influx of outside air due to a calving-mediated suboptimal closure of the vulva.

Most recently, Burdick et al. (2012) reported higher correlation $(r=0.97 ; P<0.001)$ utilizing 5 Brahman heifers between continuously measured RT and VT but with two different temperature loggers. The vaginal logger (Star-Oddi, DST micro-T logger, Meter Mall USA, Marysville OH, USA) was attached to a CIDR while the rectal logger, (TidbiT v2, Part UTBI-001, Onset Corp., Pocasset MA, USA) was fitted to an aluminium tail harness holding the temperature logger in place developed by Reuter et al. (2010). The above mentioned study describes the coefficient of correlation $(r)$ between the results of the two measurement methods utilizing two different types of loggers as an indicator of agreement. However, it has been demonstrated that in the analysis of measurement method comparison correlation coefficients or regression analysis alone are inappropriate (Altman \& Bland, 1983; Bland \& Altman, 2010). Such measures should be complemented by a plot of difference against the average which is more useful in almost all applications to medical measurements (Bland \& Altman, 1986). Use of an identical method (i.e. temperature loggers) to measure RT and VT in cows and interpreting their results with Bland \& Altman graphical agreement and intra-class correlation coefficients in this study shows a greater agreement for RT and VT than the previous studies.

Vickers et al. (2010) and Suthar et al. (2011) used handheld digital thermometers to measure RT, whereas in the current study RT and VT were measured using technically identical temperature loggers. Our data demonstrated a greater correlation and agreement between RT and VT in individual animals. These results suggest that devices with different accuracy and resolution could have affected the results in previous studies. Vickers et al. (2010) concluded that various changes in penetration depth, logger movement and air influx, and thermometer type could contribute to differences found between RT and VT. Temperature loggers in the current study were inserted at a minimal depth of $20 \pm 5$ and $14 \pm 3 \mathrm{~cm}$, respectively, into the rectum and the vagina. It can be suggested that a minimal depth of penetration for temperature measuring devices is necessary in order to minimize the influence of environmental factors.

Temperature loggers have been used in livestock research for decades. To our knowledge this is the first study which compared VT and RT with identical temperature measuring devices while previous studies used thermometers or rectal temperature monitoring device (Burdick et al. 2012) to measure RT and temperature loggers in the vaginal cavity (e.g. Kendall et al. 2006; Vickers et al. 2010). We assume that the use of different measuring devices affected the results in those studies. Overall, continuous VT monitoring can provide a close measure of BT since coefficient of correlation and an agreement was high and differences between VT and RT were negligible. 
We thank the staff of the Department of Biochemistry, Faculty of Veterinary Medicine, Freie Universität, Berlin, Germany for providing necessary laboratory facilities for the part of study performed in vitro and the cooperation of the farm personnel during the part of study carried out in vivo.

\section{References}

Altman DG \& Bland JM 1983 Measurement in medicine: the analysis of method comparison studies. Journal of the Royal Statistical Society. Series $D$ (The Statistician) 32 307-317

AIZahal O, AIZahal H, Steele MA, Van Schaik M, Kyriazakis I, Duffield TF \& McBride BW 2011 The use of a radio telemetric ruminal bolus to detect body temperature changes in lactating dairy cattle. Journal of Dairy Science 94 3568-3574

Bergen RD \& Kennedy AD 2000 Relationship between vaginal and tympanic membrane temperature in beef heifers. Canadian Journal of Animal Science 80 515-518

Bewley JM, Einstein ME, Grott MW \& Schutz MM 2008 Comparison of reticular and rectal core body temperatures in lactating dairy cows. Journal of Dairy Science 91 4661-4672

Bitman J, Lefcourt A, Wood DL \& Stroud B 1984 Circadian and ultradian temperature rhythms of lactating dairy cows. Journal of Dairy Science $\mathbf{6 7}$ 1014-1023

Bland JM \& Altman DG 2010 Statistical methods for assessing agreement between two methods of clinical measurement. International Journal of Nursing Studies 47 931-936

Bland MJ \& Altman DG 1986 Statistical methods for assessing agreement between two methods of clinical measurement. Lancet 327 307-310

Burdick NC, Carroll JA, Dailey JW, Randel RD, Falkenberg SM \& Schmidt TB 2012 Development of a self-contained, indwelling vaginal temperature probe for use in cattle research. Journal of Thermal Biology 37 339-343

Burfeind O, von Keyserlingk MAG, Weary DM, Veira DM \& Heuwieser W 2010 Short communication: repeatability of measures of rectal temperature in dairy cows. Journal of Dairy Science 93 624-627

Burfeind O, Suthar VS, Voigtsberger R, Bonk S \& Heuwieser W 2011 Validity of prepartum changes in vaginal and rectal temperature to predict calving in dairy cows. Journal of Dairy Science 94 5053-5061

Day TK \& Skarda RT 1991 The pharmacology of local anesthetics. Veterinary Clinics of North America-Equine Practice 7 489-500

Dikmen S, Alava E, Pontes E, Fear JM, Dikmen BY, Olson TA \& Hansen PJ 2008 Differences in thermoregulatory ability between slick-haired and wild-type lactating Holstein cows in response to acute heat stress. Journal of Dairy Science 91 3395-3402

Drillich M, Beetz O, Pfützner A, Sabin M, Sabin HJ, Kutzer P, Nattermann H \& Heuwieser W 2001 Evaluation of a systemic antibiotic treatment of toxic Puerperal Metritis in dairy cows. Journal Dairy Science $\mathbf{8 4} 2010$ 2017

Field A 2005 Discovering Statistics Using SPSS, 3rd edition. 1 Oliver's Yard, 55 City road, London: SAGE Publications Ltd

Kahn CM \& Line S 2010 The Merck Veterinary Manual, 10th edition. Whitehouse Station, NJ, USA: Merck Sharp \&Dohme Corp., a subsidiary of Merck \& Co., Inc
Kendall PE \& Webster JR 2009 Season and physiological status affects the circadian body temperature rhythm of dairy cows. Livestock Science $\mathbf{1 2 5}$ 155-160

Kendall PE, Nielsen PP, Webster JR, Verkerk GA, Littlejohn RP \& Matthews LR 2006 The effects of providing shade to lactating dairy cows in a temperate climate. Livestock Science 103 148-157

Kendall PE, Tucker CB, Dalley DE, Clark DA \& Webster JR 2008 Milking frequency affects the circadian body temperature rhythm in dairy cows. Livestock Science 117 130-138

Lammoglia MA, Bellows RA, Short RE, Bellows SE, Bighorn EG, Stevenson JS \& Randel RD 1997 Body temperature and endocrine interactions before and after calving in beef cows. Journal of Animal Science $\mathbf{7 5}$ 2526-2534

Lefcourt AM \& Adams WR 1998 Radiotelemetric measurement of body temperature in feedlot steers during winter. Journal of Animal Science $\mathbf{7 6}$ 1830-1837

Rajamahendran R, Robinson J, Desbottes S \& Walton JS 1989 Temporal relationships among estrus, body temperature, milk yield, progesterone and luteinizing hormone levels, and ovulation in dairy cows. Theriogenology 31 1173-1182

Reuter RR, Carroll JA, Hulbert LE, Dailey JW \& Galyean ML 2010 Technical note: development of a self-contained, indwelling rectal temperature probe for cattle research. Journal of Animal Science 88 3291-3295

Rose-Dye TK, Burciaga-Robles LO, Krehbiel CR, Step DL, Fulton RW, Confer AW \& Richards CJ 2011 Rumen temperature change monitored with remote rumen temperature boluses after challenges with bovine viral diarrhea virus and Mannheimiahaemolytica. Journal of Animal Science 89 1193-1200

Sheldon IM, Williams EJ, Miller ANA, Nash DM \& Herath S 2008 Uterine diseases in cattle after parturition. Veterinary Journal 176 115-121

Skarda RT \& Muir WW 1979 Segmental lumber epidural analgesia in cattle. American Journal of Veterinary Research $4052-57$

Suthar VS, Burfeind O, Patel JS, Dhami AJ \& Heuwieser W 2011 Body temperature around induced estrus in dairy cows. Journal of Dairy Science 94 2368-2373

Suthar V, Burfeind O, Bonk S, Voigtsberger R, Keane C \& Heuwieser W 2012a Factors associated with body temperature of healthy Holstein dairy cows during the first 10 days in milk. Journal of Dairy Research $\mathbf{7 9}$ 135-142

Suthar VS, Burfeind O, Bonk S, Dhami AJ \& Heuwieser W 2012b Endogenous and exogenous progesterone influence body temperature in dairy cows. Journal of Dairy Science 95 2381-2389

Vickers LA, Burfeind O, von Keyserlingk MAG, Veira DM, Weary DM \& Heuwieser W 2010 Technical note: comparison of rectal and vaginal temperatures in lactating dairy cows. Journal of Dairy Science 93 5246-5251

Watson PF \& Petrie A 2010 Method agreement analysis: a review of correct methodology. Theriogenology 73 1167-1179

Wenz JR, Moore DA \& Kasimanickam R 2011 Factors associated with the rectal temperature of Holstein dairy cows during the first 10 days in milk. Journal of Dairy Science 94 1864-1872

Wrenn TR, Bitman J \& Sykes JF 1958 Body temperature variations in dairy cattle during the estrous cycle and pregnancy. Journal of Dairy Science 41 1071-1076

Wrenn TR, Bitman J \& Sykes JF 1961 Diurnal patterns of bovine body temperature. Journal of Dairy Science $4 \mathbf{4} 2077-2080$ 